\title{
Preoperative Oral Supplementation with Long-Chain $\Omega-3$ Fatty Acids Beneficially Alters Phospholipid Fatty Acid Patterns in Liver, Gut Mucosa, and Tumor Tissue
}

\author{
Metin Senkal, MD*; Rolf Haaker, MD*; Jakob Linseisen, PhD†; Günther Wolfram, MD‡; \\ Heinz-Herbert Homann, MD*; and Peter Stehle, PhDI \\ From the *Department of Surgery, St. Josef Hospital, Ruhr University, Bochum, Germany; the †German Cancer Research Center, Heidelberg, Germany; \\ the $\ddagger$ Institute for Nutrition Science, Technical University Munich, Freising, Germany; and the IDepartment of Nutrition Science, University of Bonn, \\ Bonn, Germany
}

\begin{abstract}
Background: The uptake of $\omega-3$ polyunsaturated fatty acids (PUFAs) into the liver, gut mucosa, and tumor tissue and plasma levels after preoperative administration of supplemented enteral nutrition was investigated in patients with malignancies of the upper gastrointestinal tract. The objective of the study was to evaluate the incorporation of preoperatively administrated PUFAs, eicosapentaenoic acid (EPA), and docosahexaenoic acid (DHA) into cell phospholipids. Methods: Patients undergoing major gastrointestinal surgery $(\mathrm{n}=40)$ were prospectively randomized to receive a PUFA-supplemented liquid oral diet 5 days preoperatively or an isocaloric control diet. The planned diet intake was 1000 $\mathrm{mL} / \mathrm{d}$ providing $3.7 \mathrm{~g}$ of PUFA. The diet was given in addition to the usual hospital diet. The phospholipid fractions in plasma were analyzed on the day of surgery. Tissue samples of liver, gut mucosa (small intestine), and tumor were taken during surgery and homogenized. EPA and DHA content was analyzed using liquid gas chromatography. Results: Both
\end{abstract}

The dietary fatty acids of the $\omega-3$ series are rapidly incorporated into cell membranes and profoundly influence biologic responses. These lipids influence membrane stability, membrane fluidity, cell mobility, the formation of receptors, binding of ligands to their receptors, activation of intracellular signaling pathways either directly or through the formation of eicosanoids, gene expression, and cell differentiation. In general, eicosanoids formed from the $\omega$-3 fatty acids are much less potent in causing biologic responses, including stimulation of cytokine production and inflammatory responses, than those formed from the $\omega-6$ fatty acids.

It is now widely accepted that long-chain polyunsaturated fatty acids are not only used as energy-providing substrates but possess important additional functions as building blocks for cell membranes and as precursors of eicosanoids and cytokines. ${ }^{1}$ Most impor-

Correspondence: Metin Senkal, MD, Department of Surgery, Marienhospital Witten, Marienplatz 2, 58452 Witten, Germany. Electronic mail may be sent to senkal@marien-hospital-witten.de. patient groups (PUFA group: $\mathrm{n}=20$; control group: $\mathrm{n}=20$ ) were similar in age, weight, and surgical procedures. As compared with the control group, the PUFA group had significantly increased levels of EPA in liver tissue (0.4 vs 1.3 weight \%), gut mucosa ( 0.3 vs 1.0 weight \%), and tumor tissue (0.3 vs 0.8 weight \%). Also, the DHA levels in the PUFA group were significantly higher than the control group: liver tissue (4.1 vs 7.5 weight \%), gut mucosa (2.1 vs 3.7 weight \%) and tumor tissue (1.9 vs 4.2 weight \%). Conclusions: This study suggests that administration of PUFA-enriched diets leads to increased incorporation of EPA and DHA not only in liver and gut mucosa tissue, but also in tumor tissue in patients with solid gastrointestinal tumors. Thus, preoperative administration of oral PUFA-enriched diets could have an impact on the postoperative inflammatory response after major abdominal surgery.

tantly, the ratio of $\omega-6$ to $\omega-3$ fatty acids bound in cell membrane phospholipids alter eicosanoid synthesis: a low ratio (high percentage of $\omega-3$ ) can markedly suppress generation of proinflammatory cytokines. ${ }^{2,3}$ At least a part of the inflammation exacerbation postsurgery is due to generation of proinflammatory mediators such as leukotrienes (LTBs) and prostaglandins. $\Omega-6$ fatty acids serve as precursors of inflammatory mediators associated with injury and the stress response. ${ }^{4}$ In contrast, the antiinflammatory effects of $\omega-3$ fatty acids have been well documented in both, animals and humans. The antiinflammatory properties of $\omega-3$ fatty acids have also been demonstrated in injured animals, as manifested by reductions in metabolic rates, normalization of glucose metabolism, overall weight loss, nitrogen balance, and immune function. ${ }^{5,6}$ It can thus be hypothesized that any preoperative nutrition support beneficially modifying cell membrane composition may influence the course and the magnitude of the sequences of proinflammatory cascades after trauma.

Recent investigations in enteral nutrition have focused on the ability to modulate the immune response to injury via specially formulated enteral diets. Immunonutrition using nutrients such as argi- 
nine, RNA, and $\omega-3$ fatty acids, which are provided in fish oil, has been used to alter eicosanoid synthesis, cytokine production, and immune function in an attempt to limit the undesired immune reactions after surgical injury. ${ }^{7-11}$

In a prospective, randomized, double-blind clinical trial, we investigated the effects of a preoperative oral supplement enriched with arginine, RNA, and longchain polyunsaturated fatty acids on tissue levels of polyunsaturated fatty acids (PUFA). In the present paper, we evaluate the incorporation of the long chain $\omega-3$, eicosapentaenoic acid (EPA), and docosahexaenoic acid (DHA) in the liver, gut, and tumor tissue compared with serum levels after a 5-day period of preoperative oral supplementation in patients with upper gastrointestinal malignancies.

\section{MATERIALS AND METHODS}

The study was carried out as a prospective randomized double-blinded trial. Written informed consent was obtained from each patient after approval by the Human Investigation Committee of the Ruhr-University Bochum. In all, 40 consecutive patients 18-80 years of age with histologically documented malignancies of the upper gastrointestinal tract that required surgery were enrolled into the study.

\section{Interventions}

The patients were randomized into 2 groups $(\mathrm{n}=20)$ to receive either $1000 \mathrm{~mL}$ of the study diet per day for 5 days preoperatively (Oral IMPACT, Novartis Nutrition, Bern, Switzerland) or the same amount of an isocaloric control diet without supplementation of $\omega-3$ fatty acids in addition to the usual hospital diet. The composition of both formulas is listed in Table I. Exclusion criteria were total intake of the study diet of $<3000 \mathrm{~mL}$ preoperatively, the presence of endocrine or metabolic disorders, any known allergic diseases, hemorrhagic diathesis, sepsis or preexisting severe chronic disease including renal or liver failure, or congestive heart failure. Patients who received any immunosuppressive medication or chemotherapy and radiotherapy in the last 3 months before surgery were excluded from the protocol. Other exclusion criteria were drug abuse, emergency surgery, or inadequate preoperative preparation and intake of medications affecting eicosanoid metabolism in the 2 weeks before surgery.

All patients underwent surgical procedures as indicated by their primary site and stage of disease (Table II). A single dose of antibiotics (cephalosporin) was given IV 30 minutes before surgery to each patient. Anesthetic procedures during surgery were comparable in both groups, as were time of surgery and blood loss. During surgery, samples of the liver, ileum mucosa, and tumor tissue were obtained and immediately deep frozen on dry ice, a whole blood sample was drawn, and the separated serum was frozen at $-20^{\circ} \mathrm{C}$.

\section{Biochemical Analyses}

The lipids from serum samples and homogenized tissue samples were extracted using chloroform:meth-
TABLE I

Composition of the preoperative powder diets per portion

\begin{tabular}{|c|c|c|}
\hline Daily dose & $\begin{array}{l}\text { Polyunsaturated } \\
\text { fatty acid diet }\end{array}$ & Control diet \\
\hline Content (g) & 74 & 74 \\
\hline Protein (g) & 16.7 & 13.0 \\
\hline Whey & 13 & 13 \\
\hline L-Arginine & 3.74 & - \\
\hline Glycine & - & - \\
\hline $\begin{array}{l}\text { Glycine, L-Serine, L-Proline, } \\
\text { L-Alanine }\end{array}$ & - & - \\
\hline Fatty acids (g) & 8.3 & 8.3 \\
\hline Essential & $(0.94)$ & $(2.6)$ \\
\hline$\Omega-6$ & $(0.86)$ & $(2.6)$ \\
\hline$\Omega-3$ & (1) & \\
\hline Carbohydrates (g) & 40.2 & 43.94 \\
\hline Fiber $(\mathrm{g})$ & 3 & 3 \\
\hline RNA (mg) & 390 & - \\
\hline Nitrogen (g) & 3.3 & 2.1 \\
\hline Energy (kcal) & 303 & 303 \\
\hline Protein: fat: carbohydrates (\%) & $22: 25: 53$ & $17: 25: 58$ \\
\hline Sodium (mg) & 320 & 320 \\
\hline Potassium (mg) & 402 & 402 \\
\hline Calcium (mg) & 240 & 240 \\
\hline Magnesium (mg) & 80 & 80 \\
\hline Phosphorus (mg) & 216 & 216 \\
\hline Chloride (mg) & 480 & 480 \\
\hline Iron $(\mathrm{mg})$ & 3.6 & 3.6 \\
\hline Copper (mg) & 0.5 & 0.5 \\
\hline Manganese (mg) & 0.6 & 0.6 \\
\hline Zinc (mg) & 4.5 & 4.5 \\
\hline Fluorine (mg) & 0.5 & 0.5 \\
\hline Iodine $(\mu g)$ & 45 & 45 \\
\hline Chromium $(\mu \mathrm{g})$ & 30 & 30 \\
\hline Molybdenum ( $\mu \mathrm{g})$ & 60 & 60 \\
\hline Selenium $(\mu \mathrm{g})$ & 14 & 14 \\
\hline Retinol (vitamin A; mg) & 0.3 & 0.3 \\
\hline From beta-carotene & 0.15 & 0.15 \\
\hline Calciferol (vitamin $\mathrm{D} ; \mu \mathrm{g}$ ) & 2 & 2 \\
\hline Tocopherol (vitamin E; mg) & 4 & 4 \\
\hline As antioxidants & 12 & 12 \\
\hline Phyllochin (vitamin K1; mg) & 20 & 20 \\
\hline Thiamine (vitamin $\mathrm{B} 1 ; \mathrm{mg}$ ) & 0.36 & 0.36 \\
\hline Riboflavine (vitamin B2; mg) & 0.52 & 0.52 \\
\hline Pyridoxine (vitamin B6; mg) & 0.44 & 0.44 \\
\hline Cyanocobalt (vitamin $\mathrm{B} 12 ; \mu \mathrm{g}$ ) & 1.2 & 1.2 \\
\hline Ascorbic Acid (vitamin C; mg) & 20 & 20 \\
\hline As antioxidants & 80 & 80 \\
\hline Biotine $(\mu \mathrm{g})$ & 30 & 30 \\
\hline Folic acid $(\mu g)$ & 60 & 60 \\
\hline Niacinamide (mg) & 4.8 & 4.8 \\
\hline Pantothenic acid (mg) & 2.4 & 2.4 \\
\hline Choline (mg) & 80 & 80 \\
\hline Osmolarity $(\mathrm{mOsm} / \mathrm{L})$ & $\begin{array}{l}477-509, \\
\text { depending on } \\
\text { flavor }\end{array}$ & $\begin{array}{l}\sim 310 \text {, depending } \\
\quad \text { on flavor }\end{array}$ \\
\hline
\end{tabular}

1 portion $=$ content of sachet to be dissolved in $250 \mathrm{~mL}$ water.

anol (2:1). Phospholipids of serum and tissue samples were separated by thin layer chromatography using petroleum ether:ethylmethylketone:acetic acid (84:15:1) as a solvent. Fatty acid methyl esters were obtained by transesterferication with trimethysulphonium hydroxide and separated by use of a CP-Sil-99 (Chrompack, Frankfurt, Germany) capillary column, installed in an HP 5890 gaschromatograph with flame ionization detector (Hewlett Packard, Taufkirchen, Germany). ${ }^{5}$ For separation and identification of the fatty acid methyl ester peaks, standard reagents of analytical grade were used. 
TABLe II

Patient data

\begin{tabular}{lcc}
\hline \multicolumn{1}{c}{ Variable } & $\begin{array}{c}\text { Polyunsaturated } \\
\text { fatty acid group }\end{array}$ & $\begin{array}{c}\text { Control } \\
\text { group }\end{array}$ \\
\hline$n$ & 20 & 20 \\
Age (years) & $79 \pm 9$ & $75 \pm 13$ \\
Gender (m:f) & $12: 8$ & $14: 6$ \\
Weight (kg) & $74 \pm 11$ & $75 \pm 15.5$ \\
Karnofsky index & $81 \pm 11$ & $79 \pm 10.5$ \\
Surgical procedures & & 4 \\
$\quad$ Esophageal resection & 4 & 6 \\
Gastrectomy & 8 & 5 \\
$\quad$ Gastric resection & 1 & 3 \\
$\quad$ Duodenohemipancreatectomy & 3 & 265 \\
$\quad$ Others & 260 & $765 \pm 633$ \\
Mean operation time (min) & $635 \pm 676$ & $2.1 \pm 0.5$ \\
Blood loss (ml) & $1.9 \pm 0.3$ &
\end{tabular}

Data are means $\pm \mathrm{SD}$.

\section{Statistical Analysis}

The data are expressed as means \pm SD. Significance testing for the univariate, between group differences was performed using, where appropriate, exact Wilcoxon test. Two tailed $p$ values $<.05$ were considered significant. The data analysis was performed on SAS 6.0 .

\section{RESULTS}

There were no differences between the 2 groups with respect to age, sex distribution, preoperative diagnoses, or operative procedures (Table II). The 2 groups were comparable regarding preoperative nutrition status, mean percent usual body weight, mean operative duration, or intraoperative blood transfusion.

Mean preoperative intake of enteral formula was $3395 \mathrm{~mL}( \pm 730 \mathrm{~mL})$ in the PUFA group and $3450 \mathrm{~mL}$ $( \pm 395 \mathrm{~mL})$ in the placebo group. Gastrointestinal tolerance of both diets was good.

In the PUFA group, EPA and DHA levels were significantly higher in patients receiving the supple- mented diet. Highest mean weight percents of EPA and DHA levels were found in serum specimens, but there was also a significant increase of both DHA and EPA levels in the bulk phospholipids in tumor tissue (Figs. 1 and 2). The most apparent differences in EPA levels were seen in liver and gut mucosa, whereas greatest differences in DHA levels were seen in tumor tissue.

\section{DISCUSSION}

In this prospectively randomized study, we demonstrated that 5 days of oral administration of an $\omega-3$ fatty acid enriched diet was appropriate to significantly increase the content of PUFA in the serum and in the liver, ileal mucosa, and tumor tissues of patients with gastrointestinal tumors. Application of $\omega$-3 fatty acids was demonstrated in various animal models and in humans to improve host defense mechanisms, ${ }^{10,12}$ and despite some concerns on a further suppression of cell-mediated immune mechanisms in immune compromised patients, fish oils have been used successfully in the management of several inflammatory, cardiovascular, and autoimmune diseases. ${ }^{1,13-15}$

Early postoperative enteral immunonutrition including fish oil has been shown to be effective on the immune response to trauma and surgical procedures. ${ }^{12}$ However, the modulation of immune parameters in cancer patients who were fed with an immune modulating diet postoperatively took place after $5-7$ days. ${ }^{10}$ This was accompanied by clinical effects, which were apparent after 5 days (eg, reduction in infection rate). ${ }^{11}$ By contrast, administration of $\omega-3$ fatty acids and other immunonutrients for 7 days preoperatively and in the postoperative period significantly reduced postoperative infections and length of hospital stay overall. ${ }^{8,16}$ These data led to the hypothesis that a "preloading" of cell membrane phospholipids with active precursors of desirable immune modulators is beneficial for patient recovery, independent of the general nutrition status. ${ }^{17}$

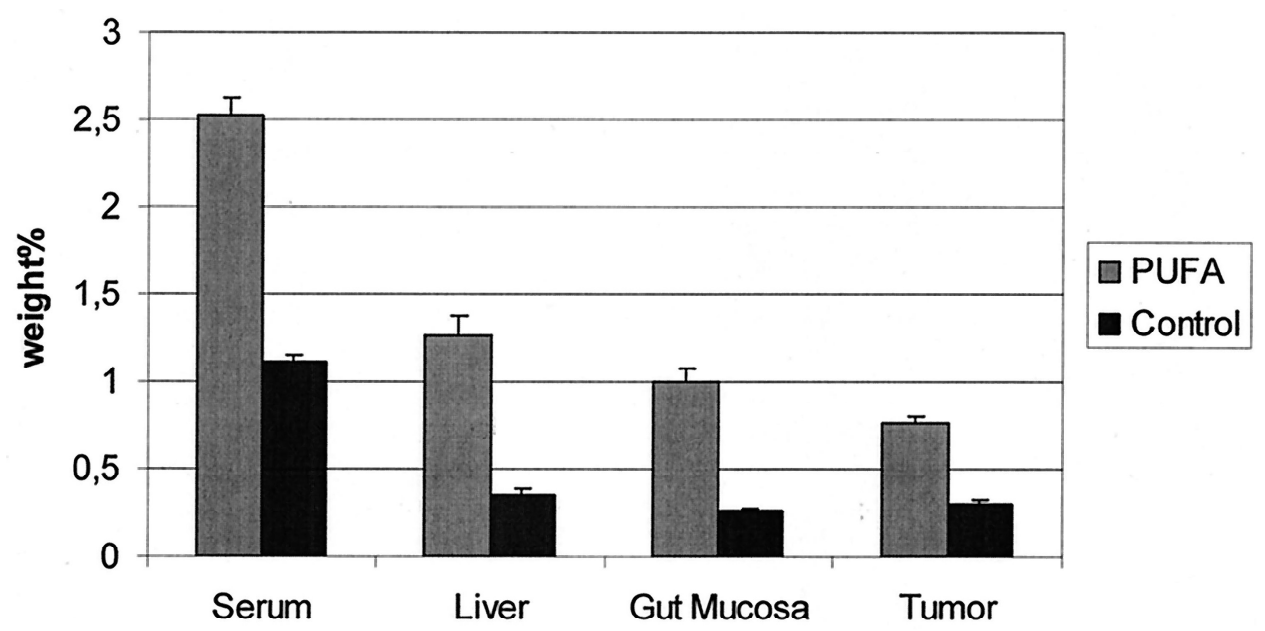

FIG. 1. Eicosapentaenoic acid (EPA) content ( \pm SD) in different tissue cells and in serum samples taken during surgery in the group receiving $\omega$-3 fatty acid supplemented diet (PUFA) $v$ s the control group determined by capillary gas chromatography. EPA content was significantly higher in the PUFA group compared with the control group in all tissues $(p<.05)$. 


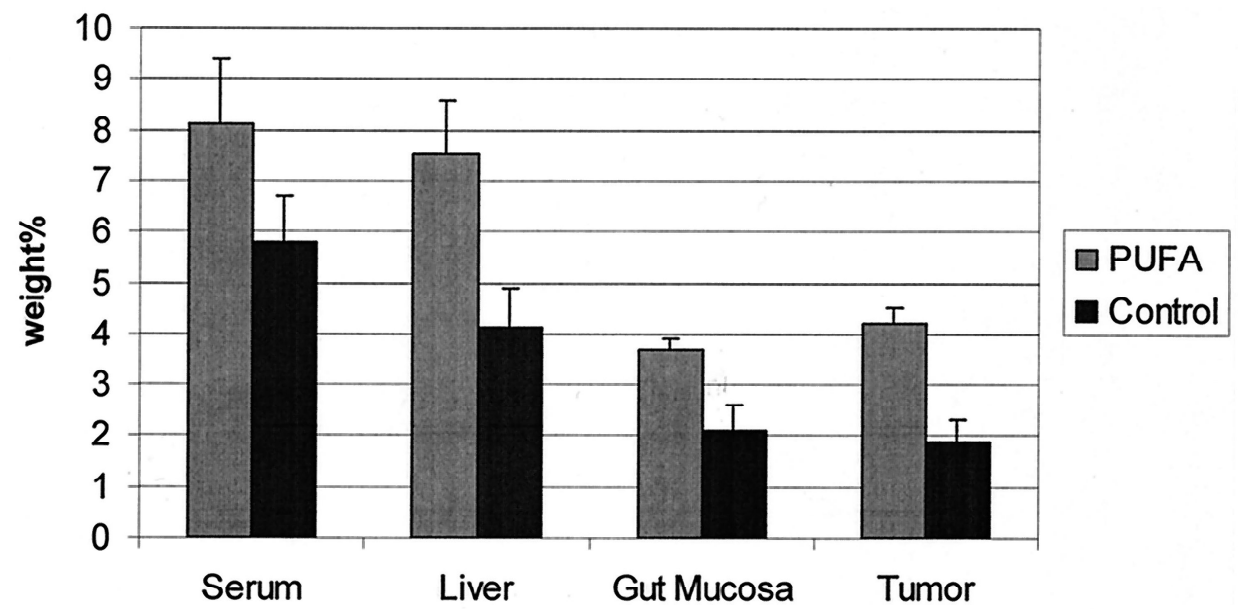

Fig. 2. Docosahexaenoic acid (DHA) content in different specimens taken intraoperatively in the group receiving $\omega$-3 fatty acid supplemented diet (PUFA) vs the control group. DHA was determined by capillary gas liquid chromatography. DHA content was significantly higher in the immunonutrition group compared with the control group in all tissues $(p<.05)$

Interestingly, perioperative fish oil supplementation including a short preoperative parenteral administration of $\omega-3$ fatty acids significantly reduced mortality rates. ${ }^{17}$ This is explained by beneficial effects of modulation of eicosanoid and cytokine biology. IV infusion of fish oil rapidly leads to incorporation of $\omega-3$ fatty acids in leukocyte cell membranes phospholipids in healthy adults ${ }^{18,19}$ and in different patient groups. ${ }^{3,20-24}$ Perioperative infusion of EPA counteracts the fall of cell-mediated immunity after chemoradiation therapy in esophageal cancer patients as outlined by natural killer cell activity and lymphocyte proliferation. ${ }^{25} \mathrm{~A}$ higher ratio of $\omega-3$ to $\omega-6$ fatty acids in membrane phospholipids is associated with a reduced production of proinflammatory cytokines like interleukin (IL)- $1 \alpha$, IL-1 $\beta$, IL-6 and tumor necrosis factor- $\alpha$ in response to an inflammatory stimulus. ${ }^{26,27}$ It is also likely that a preoperative administration of $\omega-3$ fatty acids promotes the endogenous synthesis of antiinflammatory LTBs of series 5 .

The aim of the present study was to evaluate the alteration of lipid composition of the cell membranes in different tissues due to immunonutrition by determining the composition of bulk phospholipids of different cell types. Arachidonic acid (AA) and EPA are incorporated into leukocyte phospholipids under dietary conditions. ${ }^{28}$ The enzymes which produce proinflammatory lipid mediators (eg, $\mathrm{LTB}_{4}$ ) from AA also metabolize EPA and DHA to less inflammatory active mediators like $\mathrm{LTB}_{5}$. Therefore, higher levels of EPA and DHA may lead to a decrease in $\mathrm{LTB}_{4}$ generation with higher levels of less biologically active mediators such as $\mathrm{LTB}_{5}$. This increase in $\mathrm{LTB}_{5}$ generation with a change in the $\mathrm{LTB}_{4} / \mathrm{LTB}_{5}$ ratio was shown in a study where patients were fed with an immune modulating diet preoperatively. ${ }^{24}$ In the present study, the 2 patient groups were comparable regarding age, sex, weight, nutrition status, disease, and operation. During the observation period, nutrition support in terms of caloric intake was equal, but the supplemented group received significantly higher amounts of $\omega-3$ fatty acids, arginine, and RNA nucleotides. The results of lipid composition in the investigated tissues indicate the incorporation of EPA and DHA into the cell membranes of different tissues. Because the $\omega-3$ fatty acids undergo a prolonged kinetic process in contrast to the other immune-modulating nutrients (eg, arginine), a 5-day course of oral administration seems to be long enough for incorporation of $\omega-3$ fatty acids into the cell membranes, in contrast to IV $\omega-3$ fatty acid administration, where the incorporation into cell membranes has been shown to be much faster. ${ }^{29}$

In summary, the study clearly demonstrates that preoperative oral immunonutrition with $\omega-3$ fatty acids will change the lipid profile of different tissues and lipid composition of the serum. Thereby, these data support the hypothesis that "preloading" the cell membrane phospholipids with active precursors is possible by preoperative dietary administration of $\omega$-3 fatty acids. Due to a decrease in generation of active lipid metabolites from AA, the immune depression after surgical trauma might be diminished. Beside this, incorporation of EPA into tumor cells was associated with a higher sensitivity to chemotherapy in an in vitro model. ${ }^{30}$ The use of preoperative nutrition in cancer patients with immunonutrients such as $\omega-3$ fatty acids must be therefore reevaluated on the background of immune modulation, which might have a beneficial effect on the postoperative course.

\section{REFERENCES}

1. Furst P, Kuhn KS. Fish oil emulsions: what benefits can they bring? Clin Nutr. 2000;19:7-14.

2. Grimm H, Mayer K, Mayser P, Eigenbrodt E. Regulatory potential of n-3 fatty acids in immunological and inflammatory processes. Br J Nutr. 2002;87(suppl):S59-S67.

3. Köller M, Senkal M, Kemen M, König W, Zumtobel V, Muhr G. Impact of omega-3 fatty acid enriched PN on leukotriene synthesis by leukocytes after major surgery. Clin Nutr. 2003;22:59-64.

4. Kinsella JE, Lokesh B. Dietary lipids, eicosanoids and the immune system. Crit Care Med. 1999;18:94-113.

5. Sierra P, Ling PR, Istfan NW, Bistrian BR. Fish oil feeding improves muscle glucose uptake in tumor necrosis factor-treated rats. Metabolism. 1995;44:1365-1370.

6. Trocki O, Heyd TJ, Waymack JP, Alexander JW. Effects of fish oil on postburn metabolism and immunity. JPEN J Parenter Enteral Nutr. 1987;11:521-528. 
7. Alexander JW. The role of immunonutrition in reducing complications following organ transplantation. Transplant Proc. 2000; 32:574-575.

8. Beale RJ, Bryg DJ, Bihari DJ. Immunonutrition in the critically ill: a systematic review of clinical outcome. Crit Care Med. 1999; 27:2799-2805.

9. Braga M, Gianotti L, Vignali A, Carlo VD. Preoperative oral arginine and $n-3$ fatty acid supplementation improves the immunometabolic host response and outcome after colorectal resection for cancer. Surgery. 2002;132:805-814.

10. Kemen M, Senkal M, Homann H-H, Zumtobel V. Early postoperative enteral nutrition with arginine, omega-3-fatty acids and ribonucleic acid-supplemented diet versus placebo in cancer patients: an immunologic evaluation of Impact. Crit Care Med. 1995;23:652-659.

11. Senkal M, Mumme A, Eickhoff U, Geier B, Späth A, Kemen M. Early postoperative immunonutrition: clinical outcome and costcomparison analysis in surgical patients. Crit Care Med. 1997; 25:1489-1496.

12. Daly JM, Lieberman MD, Goldfine J. Enteral nutrition with supplemental arginine, RNA, and omega-3 fatty acids in patients after operation: immunologic, metabolic, and clinical outcome. Surgery. 1992;112:56-67.

13. Kremer JM. n-3 fatty acid supplements in rheumatoid arthritis. Am J Clin Nutr. 2000;71(suppl):S349-S351.

14. Segal-Isaacson CJ, Wylie-Rosett J. The cardiovascular effects of fish oils and omega-3 fatty acids. Heart Dis. 1999;1:149-154.

15. Takatsuka H, Takemoto J, Iwata N. Oral eicosapentaenoic acid for complications of bone marrow transplantation. Bone Marrow Transpl. 2001;28:769-774.

16. Braga M, Gianotti L, Radaelli G, et al. Perioperative immunonutrition in patients undergoing cancer surgery: results of a randomized double-blind phase 3 trial. Arch Surg. 1999;134:428433.

17. Tsekos E, Reuter C, Stehle P, Boeden G. Perioperative administration of parenteral fish oil supplements in a routine clinical setting improves patient outcome after major abdominal surgery. Clin Nutr. 2004;23:325-330.

18. Elmadfa I, Stroh WS, Brandt K, Schlotzer E. Influence of a single parenteral application of a $10 \%$ fish oil emulsion on plasma fatty acid pattern and the function of thrombocytes in young adult men. Ann Nutr Metab. 1993;37:8-13.

19. Herrmann A, Döhla A, Hailer S, Wolfram G, Jauch KW. Der Einfluss omega-3-fettsäurehaltiger Emulsionen auf das Immun- system gesunder Probanden unter Berücksichtigung der Fettsäurenzusammensetzung von Blutfetten und Zellmembranen. Aktuel Ernähr-Med. 1996;21:63-64.

20. Ikehata A, Hiwatashi N, Kinouchi Y, Yamazaki H, Ito K, Toyota T. Effect of intravenously infused eicosapentaenoic acid on the leukotriene generation in patients with active Crohn's disease. Am J Clin Nutr. 1992;56:938-942.

21. Mayer K, Gokorsch S, Fegbeutel C. Parenteral nutrition with fish oil modulates cytokine response in patients with sepsis. Am J Respir Crit Care Med. 2003;167:1321-1328.

22. Morlion BJ, Torwesten E, Lessire A. The effect of parenteral fish oil on leucocyte membrane fatty acid composition and leuktriene-synthesizing capacity in postoperative trauma. Metabolism. 1996;45:1208-1213.

23. Roulet M, Frascarolo P, Pilet M, Chapuis G. Effects of intravenously infused fish oil on platelet fatty acid phospholipids composition and on platelet function in postoperative trauma. JPEN J Parenter Enteral Nutr. 1997;21:296-301.

24. Wachtler P, Hilger RA, Koenig W, Bauer KH, Kemen M, Koeller $\mathrm{M}$. Influence of a preoperative enteral supplement on functional activities of peripheral leukocytes from patients with major surgery. Clin Nutr. 1995;14:275-282.

25. Takagi K, Yamamori H, Furukawa K, Miyazaki M, Tashiro T. Perioperative supplementation of EPA reduces immunosuppression induced by postoperative chemoradiation therapy in patients with esophageal cancer. Nutrition. 2001;17:478-479.

26. Caughey GE, Mantzoris E, Gibson RA, Cleland LG. The effect of human tumor necrosis factor alpha and interleukin 1 beta production of diets enriched in n-3 fatty acids from vegetable and fish oil. Am J Clin Nutr. 1996;63:116-122.

27. Enders S, Ghorbani R, Kelly VE. The effect of dietary supplementation with $n-3$ polyunsaturated fatty acid on the synthesis of IL-1 and TNF alpha by mononuclear cells. $N$ Engl J Med. 1989;320:265-271.

28. Ling PR, Boyce P, Bistrian BR. Role of arachidonic acid in the regulation of the inflammatory response in TNF-alpha-treated rats. JPEN J Parenter Enteral Nutr. 1998;22:268-275.

29. Carpentier YA, Simoens C, Siderova V. Recent developments in lipid emulsions: relevance to intensive care. Nutrition. 1997;13: 73-78.

30. Das UN, Madhavi N, Sravan Kumar G, Padma M, Sangeetha P. Can tumour cell drug resistance be reversed by essential fatty acids and their metabolites. Prostaglandins Leukot Essent Fatty Acids. 1998;58:39-54. 